\title{
Atların Yarış ve Yarışma Performansları Üzerine Etkili Faktörler ve Performansi Artırma Yolları
}

Abdurrahman Köseman ${ }^{1}$, İbrahim Şeker ${ }^{2 *}$

\author{
${ }^{1}$ İnönü Üniversitesi Akçadağ MYO, Bitkisel ve Hayvansal Üretim Bölümü, Malatya-TÜRKIYYE \\ ${ }^{2}$ Fırat Üniversitesi Veteriner Fakültesi Zootekni Anabilim Dalı, Elazığ-TÜRKIYE
}

Received 12.02.2018 Accepted 26.03.2018

\begin{abstract}
Özet
Kantitatif bir karakter olan atların yarış ve yarışma performansı genetik ve çevresel faktörlerin etkisinde şekillenmektedir. Bu nedenle bireyler ve populasyonlar arasında varyasyon bulunmaktadır. Genetik etki, tayın anasından ve babasından aldığı genlerden dolayı sahip olduğu genotip kapasitesini ifade etmektedir. Performansı etkileyen çevresel faktörler arasında; cinsiyet, yaş, doğum ağırlı̆̆ı, mesafe, handikap ağırlı̆̆ı, pist tipi ve parkur yapısı, ana yaşı, konulan ikramiye, koşan at sayısı, atın pistteki koştuğu yer, binici deneyimi gibi faktörler yer almaktadır. Bu derlemenin amacı, atların yarış ve yarışma performanslarını etkileyen genetik ve çevresel faktörler hakkında bilgi sunmaktır.

Anahtar Kelimeler: At, Yarış, Yarışma, Performans, Çevresel Faktörler, Genetik.
\end{abstract}

Factors Affecting on Race and Competition Performances of Horses and the Ways to Improve Performance

\begin{abstract}
Race and competition performance of horses, a quantitative character, is shaped by the influence of genetic and environmental factors. For this reason there are variations between individuals and populations. The genetic effect refers to the genotype capacity that is possessed by the gene from the mother and father of foal. Many environmental factors that affect performance include gender, age, birth weight, distance, handicap weight, runway type and structure, maternal age, prize, race or competition season, number of running horses, starting place, rider experience. The purpose of this review is to demonstrate factors affecting race and competition performance of horses.

Keywords: Horse, Race, Competition, Performance, Environmental Factors, Genetic.
\end{abstract}

\section{Giriş}

Atlı Sporlarda Yarış ve Yarışmanın Tanımı

Yarışma terimi binicilik sporlarında (engel atlama, at terbiyesi, üç günlük yarışma, atlı dayanıklılık, engelli biniciler, pony biniciler) organizasyonun tümü, gösteri, şampiyona veya oyunlar manasına gelmektedir. Yarışmaların yapıldığ yerler manej olarak isimlendirilmektedir. Manejler açık veya kapalı olup, at terbiyesi yarışmalarının yapıldığı manejler 60 metre uzunluğunda ve 20 metre genişliğindedir.
Engel atlama yarışmaları çeşitli konumlarda hazırlanmış engelli bir parkur üzerinde yapılmaktadır. Engel atlama yarışmalarında parkurlara konulacak engeller 80-150 cm yükseklik ve 80-170 cm genişliktedir (4-6).

At yarışları ise soy kütüğüne kayıtlı safkan Arap ve İngiliz atlarının performanslarını belirlemek amacıyla bir hipodromda kum ve çim pistlerde aynı gün yapılan koşuları ifade etmektedir (7). Yarışlar 800 ile 3400 metre arasında yapilmakta olup 1600 metreye kadar olanlar kısa, 1601-2400 metre arası olanlar orta ve 2401 metreden yukarı olanlar ise uzun mesafeli koşular olarak adlandırılmaktadır (12).

*Sorumlu Yazar: e-mail: iseker52@gmail.com Tel: +90 5336556394 e-mail: iseker52@gmail.com 
Atların yarış ve yarışma performansı; yarış süresi, bitirme sırası, ortalama yarış indeksi, yarışı kazanan ve arkadan gelenlerin uzaklıkları (performans oranları), handikap puanı-ağırlığı, parkur süresi, atların dayanıklılığı, toplam kazanç ve belli yarış veya yarışmalarda elde edilen ikramiyelere göre hesaplanmakta ve performans hesaplamalarında atların kendi kayıtlarının yanı sıra yavrularının, kollateral akrabalarının ve atalarının da kayıtlarından yararlanılmaktadır $(11,45,49)$. Ayrıca yarış hızı da atların yarış ve yarışma performanslarını kantitatif olarak değerlendirmek amacıyla kullanılabilecek kriterlerden birisidir $(20,41)$.

\section{Yarış ve Yarışma Performansını Etkileyen Faktörler ve Performansı Artırma Yolları}

Atların yarış ve yarışma performanslarını genetik ve çevresel faktörler etkilemektedir. Genetik faktörler, tayın anasından ve babasından aldığ 1 ve genlerinden ileri gelen etkileri ifade etmektedir. Genetik olan ve kalıtım derecesi olarak adlandırılan kısım, bir atın yarış performansında genlerin etki payını ya da oranını göstermektedir. Dolayısıyla yarış performansı bakımından bireyler arasında genetik farklılıklar bulunmaktadır (1).

Spor yaşamına veya yetiştirmeye alınan atlar, mümkün olan en yüksek genetik değere göre seçilmeleri gerekirken bu durum pratikte mümkün olmamaktadır. Seleksiyon, atların fenotiplerine bakılarak yapılmaktadır. Bununla birlikte genotipik değerin en güvenilir şekilde tahmin edilmesi fenotipik değerlerden yapılan hesaplamalarla mümkün olmaktadır. Dolayısıyla seleksiyon ile elde edilecek genetik ilerlemeyi sağlamak için performans üzerine etki eden çevresel faktörlerin düzeltilmesi önemlidir. Böylece özellikle kalıtım derecesi düşük olan karakterlerde seleksiyonun isabet derecesi artırılmış olmaktadır (11).

Gomez ve ark. (23) İspanyol Trotter atlarının yarış performansları üzerine yaptıkları bir araştırmada aynı mesafede yaş grupları arasındaki genetik korelasyonun 0,47 ile 0,78 olduğunu saptamışlardır.

Chrzaowski ve Koeboke, (17) atların yarış performanslarının önemli ölçüde babaların etkisinden, ana yaşından, yetiştirme şeklinden, tayların yarışlara katılma yaşından ve yarışlardaki start numaralarından etkilendikleri bildirilmiştir.

Meinardus ve Bruns, (39) dressaj ve engel atlama yarışmalarında atların performansı üzerine cinsiyet, yaş, binici deneyimi, yarışma bölgesi, yarışma mevsimi ve yılının etkisinin önemli olduğunu bildirmişlerdir.
Štrbac ve ark. (47) ise atların tırıs yarışmalarındaki performanslarını, atların doğum yılı ve ayı, cinsiyeti, yarış yılı ve mevsimi, yaşı, pist, mesafe ve başlama stili gibi faktörlerin etkilediğini kaydetmişlerdir.

Martin ve ark. (37) atların yarış performansı üzerine mesafenin, pist tipinin ve yapısının, tay yaşının, konulan ikramiye miktarı, koşu mevsiminin, koşan at sayısının, handikap ağırlığının ve atın pistteki koştuğu yerin önemli etkileri olduğunu bildirmişlerdir.

Köseman ve Özbeyaz, (33) at yarışlarında kazanılan ikramiyeye ana yaşının etkisini $\mathrm{P}<0,05$ düzeyinde; yılın, mesafenin, koşu grubunun, pistin ve tay yaşının etkilerini ise $\mathrm{P}<0,001$ düzeyinde önemli olarak tespit etmişlerdir. Atların yarış ve yarışma performansları üzerine değişik düzeylerde etkili olabilecek önemli bazı genetik ve çevresel faktörler aşağıda sıralanmıştır.

\section{Irkın Etkisi}

Yarış ve yarışma atlarının belirlenmesindeki ilk öncelik dünyada sayıları yaklaşık 500 olan (27) at ırklarından hangisinin kullanılacağına karar verilmesidir. Türkiyede safkan atlara mahsus koşulara (yarışlar), koşunun şartlarında ve yıllık yarış programları genel hükümlerinde aksi belirtilmedikçe, soy kütügüne kayıtlı safkan Arap ve İngiliz atları katılmaktadır (7).

Veno ve ark. (50) tarafından yapılmış olan bir çalışmada 2 ve 3 yaşlı İngiliz tayların yarış performanslarının kalıtım derecesi 0,17 ve tekrarlama derecesi 0,35 , Chrzaowski ve Koeboke, (17) tarafından yapılan bir çalışmada ise 2 ve 3 yaşlı İngiliz tayların yarış performanslarına ait kalıtım dereceleri sırasıyla 0,25 ve 0,18 olarak tespit edilmiştir. Arap atlarında yapılan bir çalışmada ise ortalama hızın kalıtım derecesi 0,17 olarak saptanmıştır (33).

Arıtürk ve Akandır, (11) atlarda hızın kalıtım derecesinin 0,25-0,50; dressaj, engel atlama ve konkurun 0,20; çekim gücünün ise 0,25 olduğunu bildirmektedir.

Amerika Birleşik Devletleri’nde Quarter atlarının yarış performansı üzerine yapılan bir araştırmada hızın kalıtım derecesi 0,24 ve tekrarlama derecesi 0,32 olarak hesaplanmiştır (52).

\section{Davranış ve Mizacın (Huy) Etkisi}

Atların seçiminde her zaman insanların kullanım amaçları ve ihtiyaçları önemli olmaktadır. Özellikle farklı amaçlarla (yarışlar, yarışmalar ve geleneksel sporlar) yetiştirilen ve eğitilen atların tercihinde, atların sahip oldukları morfo- 
lojik, fizyolojik, duyusal, duygusal, bilişsel, davranışsal ve sosyal özellikleri dikkate alınmaktadır. Çünkü, tercih edilen atların uygun ruhsal ve davranışsal özellikleri taşımaları, onlardan beklenen hız, sürat ve sıçrama gibi hareketleri başarılı şekilde yerine getirebilmelerine imkan sağlamaktadır. Amaca uygun özelliklere sahip atların seçimi, büyük rekabetin olduğu yarış ve yarışmalardaki başarının esas unsuru sayılmaktadır $(33,40)$.

Yapılan bir çalışmada atların her birinin farklı ve bireysel kişiliğe sahip oldukları, sevme ve hoşlanma gibi duygularının bulunduğu bildirilmiştir (9). Atların sahip oldukları davranış özellikleri, genetik ve çevresel faktörlerin etkisi altında ortaya çıkmaktadır (8). Atlarda görülebilen hırçınlık genellikle kötü muamele ya da terbiye, inatçlık kalıtımsal kaynaklı olabilmektedir Atlarda gözlenen kötü huyların düzeltilmesi çoğunlukla sonradan pek mümkün olamamaktadır (51).

Atlardaki davranışlar, farklı türlerde olduğu gibi, ırklar ve bireyler arasında da birçok farklılıklara sahip olabilmektedir. Aynı anda bir at sürüsü içerisinde çok sakin mizaçlı atlar bulunabileceği gibi çok hırçın, hareketli ve saldırgan atlar da olabilmektedir $(3,40,42)$. Atların davranış biçimleri, onların idaresi, antrenmanı, terbiyesi, iş, yarış ve yarışma performansları için çok önemli faktörlerdir $(15,38,42)$.

\section{Cinsiyetin Etkisi}

Yarış performansının atların cinsiyeti ile yakın ilişkisi olduğu, aygırların kısraklara göre daha yüksek yarış performansına sahip oldukları yapılan çalışmalarda belirlenmiştir. Buna neden olarak cinsiyetler arasındaki hormonal ve morfolojik farklılıklar gösterilmektedir (42).

Physick, (44) tarafından yapılan çalışmada kazanılan ikramiye miktarı ve yarış sayısına cinsiyetin önemli etkisi olduğu, aygırların kısraklara göre daha fazla başarı gösterdikleri belirlenmiştir.

Janczarek ve Kedzierski, (31) tarafından idmanın cinsiyetler arasındaki etkisinin kalp atım sayısı esas alınarak incelendiği bir araştırmada, antrenmandan yürüyüşe geçişteki en yüksek kalp atım sayısının oransal olarak dişi ve erkeklerin karışık olduğu grupta belirlenmiş, çalışmada ayrıca karışık cinsiyetteki tayların birlikte idman yaptırılmaları tavsiye edilmemiştir.

\section{Yaşın Etkisi}

Taylar doğumlarından itibaren yasal koşu yaşına kadar özenle bakılıp eğitilip uygun yaşta ise antrenmana tabi tu- tulurlar. Türkiye'de safkan Arap atları için yarışlara başlama yaşı 3 yaş ve İngiliz atları için 2 yaş olarak belirlenmiştir (7).

Yapılan çeşitli çalışmalarda $(17,18,30,35,50)$ yaşın koşu performansı üzerine etkisinin önemli olduğu bildirilmiştir. Lee ve ark. (36) Kore'de 5-6 yaşlı atların yarış mesafesini daha kısa sürede tamamladıklarını tespit etmişlerdir. Kiper ve ark. (32) ise yaşın etkisini 4-8 yaşlı Arap atlarında 1400 ve 2000 metre mesafeli koşularda önemli bulmazken 2600 ve 2800 metredeki koşularda önemli $(\mathrm{P}<0,05)$ bulmuşlardir.

\section{Doğum Ağırlığının Etkisi}

Tayların doğum ağırlı̆̆ı pre-natal büyümenin iyi bir ölçüsü ve erken dönemde ölçülebilen karakterlerden birisidir. Doğum ağırllğı normal ve normalin biraz üstünde olan taylarda doğum öncesi büyümenin iyi olduğu, doğum ağırlığı normalin altında düşük olan taylarda ise bu büyümenin yetersiz olduğu kabul edilir. Kendi ırkına özgü ağırlığa sahip olarak doğan taylar yaşama daha güçlü ve avantajlı başlamakta, bu üstünlüklerini yaşamlarının diğer dönemlerinde de devam ettirmektedirler (12).

\section{Ana Yaşının Etkisi}

Cothran ve ark. (19) tarafından yapılan bir çalışmada baba yaşının gebelik ve doğum oranları üzerinde herhangi bir etkisinin olmadığı, ana yaşı ile gebe kalma ve doğum oranları arasındaki ilişkinin önemli olduğu $(\mathrm{P}<0,05)$ tespit edilmiştir. Bunun dışında, ana yaşının doğum oranı üzerindeki etkisinin gebelik oranı üzerindeki etkisinden daha önemli olduğu, üreme performansı en yüksek anaların 4-15 yaşl1lar olduğu, gebelik ve doğum oranlarının 15 yaş üstü analarda keskin bir biçimde azaldığ bildirilmiştir.

Finocchio, (21) en yüksek yarış performansına sahip tayların yedi yaşlı analardan doğanlar olduğunu; Barron, (13) ise genç analardan elde edilen tayların yarışlarda daha fazla başarı gösterdiklerini ve 11 yaştan büyük analardan doğan tayların yarış performanslarının ana yaşıyla ters orantılı olarak azaldığını bildirmiştir. Arap atları üzerinde yapılan bir çalışmada en yüksek ikramiyeyi 21 yaş ve üzerindeki analardan doğan tayların kazandığı tespit edilmiştir (33).

\section{Handikap A ğırlığının Etkisi}

Handikap ağırlığ 1 jokey ve eyer ağırlığının toplamından oluşmaktadır. Binicinin can yeleği, gözlüğü, kamçısı, atın 
martingalı, gögüslük, getr, başlık ve bandajları sıklete dahil değildir (7). Handikap ve amatör binici koşuları dışındaki koşularda atların taşıyacakları ağırlıklar her yıl düzenlenen "At Yarışları Genel Hükümleri"nde bildirilmektedir. Handikap ağırlıkları gerektiğinde "Yüksek Komiserler Kurulu"nun önerisi ve Yarış Otoritesinin onayı ile değiştirilebilir $(7,10)$. Atların yarışlarda taşıyacakları ağırlık miktarları belirlenirken 1rk, yaş, cinsiyet, yarış türü, yarış mesafesi ve binicinin jokey ya da apranti oluşu dikkate alınmaktadır (12).

Handikap koşularda iki yaşlı İngiliz tayları ile üç yaşlı Arap tayları koşularında azami sıklet $58 \mathrm{~kg}$, üç yaşlı İngiliz tayları ile 4 yaşlı Arap atları koşularında azami sıklet $60 \mathrm{~kg}$, üç ve yukarı, dört ve yukarı yaşlı İngiliz atları ile 4 ve yukarı, 5 ve yukarı yaşlı Arap atları koşularında azami sıklet 63 kg’dır. Dişi atlar erkek atlarla beraber koştukları takdirde 1,5 kg eksik ağırlık taşırlar (10).

\section{Pist ve Parkurun Etkisi}

Kum ve çim pistin yapısal olarak farklı malzemelerden oluşması koşu sonuçlarını etkilemekte, yarışların bitirilme süreleri piste göre farklılık göstermektedir. Bu nedenle yarış sonuçları incelenirken, çim ve kum pistte yapılan yarışlar farklı olarak ele alınıp atların yarış performansları her pist için kendi içinde ayrı ayrı değerlendirilmektedir (7). Hintz (29) yaptı̆̆ı bir çalışmada pistin ağır ve adım aralıklarının uzun oluşunun yarış performansını olumsuz etkilediğini ortaya koymuştur.

Kumun koşular için zorlaştırıcı bir malzeme olmasından dolayı kum pistteki koşular çim pisttekilerden daha zor olmakta, buna bağlı olarak kum pistte atlar için güç ve dayanıklılık öne çımaktadır. Buna karşılık çim pistin daha elverişli olması ise çim pistte yapılan koşularda hız ve daha kısa bitirme süresinin öne çıkmasını sağlamaktadır (33).

\section{Mesafe ve Yüksekliğin Etkisi}

Atların yapısına uygun mesafeli koşularda koşturulmaları üstün yarış performanslarını ortaya koymaları ve başar1 elde etmelerinde gerekli bir durumdur. Yapısina uygun olmayan koşularda koşturulan atlar ise yarışlarda başarı kazanamamaktadırlar (43).

Harkins ve Kamerling, (26) tarafından yapılan bir çalışmada yarıs performansının orta mesafeli (1600-2400 m) koşularda yarış süresince farklı şekillendiği, bu koşularda atların belli mesafeden sonra sprint yani atak yaparak daha hızlı koştukları bildirilmiştir. Bu çalışmada atların
1200, 1600 ve 2000 metrelerde tek başlarına; 1200 ve 1600 metrelerde ise kendileriyle aynı özellikteki başka bir atla başa baş koştukları belirlenmiştir. Aksüyek, (2)'in yaptığ bir araştırmada kum pistte 1200, 1400 ve 1600 metrelerde Karacabey, 1800 metrede Anadolu İşletmesi orijinli üç yaşlı Arap taylarının daha başarılı olduklarını ve Sultansuyu orijinli atların 1800 metrede hiç koşu kazanamadıkları tespit edilmiştir.

\section{Binici ve Jokeyin Etkisi}

Bir yarışta at faktörü kadar atı idare eden ve atı koşturan jokeyin tecrübesi ve bilgisi son derece önemlidir. İki farklı canlının bütünleşerek bir arada ve aynı anda yaptığı atlı sporlarda başarı; binici ya da jokeyin atıyla meydana getirdiği zihinsel ve fiziksel koordinasyonla da yakından ilişkilidir. Bu nedenle yarışlardaki jokeyin ya da yarışmalardaki binicinin bilgi, yetenek ve tecrübesi alınacak sonuçlar bakımından oldukça önemlidir (14). Tüm sporcular gibi binici ve jokeylerin de ruhsal ve fiziksel olarak aktif olmaları, kilolarını korumaları, kötü alışkanlıklardan uzak durmaları, antrenmanlarını disiplin içerisinde yürütmeleri gerekmektedir (24).

\section{Antrenman ve Eğitimin Etkisi}

Yarış ve yarışma performansını artırmada en önemli faktörlerden birisi de teknik, bilimsel, doğru, yeterli ve amaca uygun antrenman ve eğitim programlarının uygulanmasıdır. Antrenman sayesinde aerobik liflerin miktarı artt1rılmakta, enerji sistemleri ve kaslarda glikoz depolanma kabiliyeti geliştirilmektedir. Antrenmanla artan kondisyon sayesinde yavaş kontrakte olan lifler hızlı kontrakte olan liflere dönüşmektedir. Ayrıca, antrenman tüm hareket sistemi ile birlikte yüksek performansın en önemli yapıları olan solunum ve dolaşım sistemini geliştirmektedir (24). Yarış ve yarışmalarda yüksek performans sağlamak için 6 aylık yaşta tayların eğitimine ve ırka özgü yaşta ise antrenmanlarına başlamak, hazırlık ve müsabaka dönemleri dikkate alınarak hazırlanacak günlük, haftalık, aylık ve yıllık antrenman programlarını uygulamak gerekmektedir. Antrenman programları atın fizyolojik durumuna uygun olmalı, yeterince hazır olmayan atlar yarış veya yarışmalara sokulmamalıdır (48).

\section{Beden Kondisyonunun etkisi}

Zeeb ve Schnitzer, (22) ve Garlinghouse ve Burrill, (54) yaptıkları çalışmalarda doğru beden kondisyonuna sahip 
atların, yüksek veya düşük kondisyona sahip atlara göre yarış veya yarışmalarda daha etkili performans gösterdiklerini bildirmişlerdir.

Kondisyonu iyi düzeyde olan bir yarış atında kasların iyi gelişmiş olması, vücudun atletik ve yağsız olması istenmektedir $(22,54)$. Beden kondisyonunu belirlemede ise 1-9 puanlık bir cetvel üzerinde oluşturulmuş sistem en yaygın olarak kullanılmaktadır. Bu sistem sırt ve bel bölgesi birleşme yeri, kuyruk sokumu çevresi, scapula gerisi, kaburgaların üzeri, cidago ve boyun bölgesinde depolanan yağ miktarına göre değerlendirilme yapılmasını sağlamaktadir $(16,28)$.

\section{Bakım ve Beslemenin Etkisi}

Atlar diğer hayvan türlerine göre daha hassas olduklarından özenli bakım, besleme ve yönetime ihtiyaçları vardır. Yüksek yarış ve yarışma performansı intra-uterin dönemden başlayarak uygulanacak optimum bakımla mümkün olabilmektedir. Bunun için; atlar iyi bir tavla ortamında barındırılmalı, düzenli olarak tımar edilmeli, aşıları, tırnak bakımları yapılmalı, bulundukları ortam temiz ve hijyenik olmalı, uygun yaştan itibaren eğitilmeli, daima sevgi ve şefkatle muamele edilmelidir (12).

Egzersiz atlarda besin maddeleri ihtiyacını büyük oranda artırmaktadır. At beslenmesinde grup beslemesi değil; bireysel besleme düşünülmeli ve maksimum atletik performansı sağlayacak beslenme rejimleri uygulanmalıdır (34).

\section{Sağlık Durumunun Etkisi}

Yarışmalar sırasında atların sağlığıyla ilgili ortaya çıkabilecek olumsuzlukların çok çeşitli etkileri söz konusu olabilmektedir. Bunlar, yarış ve yarışmaların organizasyon düzenlerini, yarışmalarla ilgili tüm kişi ve kurumları doğrudan etkileyecek nitelikler taşıyabilmektedir (46).

Yarış ve yarışma atlarından beklenen performansın elde edilebilmesi için çok sayıda etmenin bir arada bulunmas1 gerekir. Bu faktörlerden bir kısmı da bireysel olarak ata özgü olan ve atın bedenindeki organlar ve sistemlerle ilişkilidir.

Atlarda yarış ve yarışma performansı üzerine kalp büyüklüğü, doku düzeyindeki gaz alışverişi, enerji üretimi ve kullanımı, kasların yapısı, akciğerlerin kapasitesi, dolaşım sistemine ait özellikler (hemoglobin konsantrasyonu gibi) ve diğer biyomekanik faktörler etki yapabilmektedir. Yarış ve yarışma atlarının sahip oldukları beden özellikleri ve kapasiteleri onların sportif ve dolayısıyla yarış ve yarışma performanslarıyla yakından ilişkilidir. Bu nedenle, atların dış görünüşleri yanında yukarıda bahsedilen bedene ait fizyolojik özelliklerinin de dikkate alınması gerekmektedir. Bu sayede mevcut atlardan hangilerinin yarış veya yarışma atları, hangilerinin handikap atları olduklarının doğru şekilde belirlenmesi mümkün olabilmektedir (25).

Atlar, eğitim, antrenman, yarış ve yarışmalar sırasında tendo yırtılması, kopması, eklem bölgelerinde çıkıklar ve kemik dokularda çatlak ve kırıklar gibi sakatlanmalar yaşayabilmektedir. Diğer taraftan, atların yanlış beslenmesi (eğitim, antrenman sürecinde merada otlamak yerine yoğun tahıl içeren rasyonlarla beslemek gibi) nedeniyle özellikle ülser vakaları oldukça fazla ortaya çıkabilmektedir. Yapılan bir araştırmada, eğitim sürecinde bulunan atların \%89'unun ülsere yakalandığ 1 ve pek çoğunda, sürecin başından 8. hafta sonra derin ve kanayan ülserler meydana geldiği kaydedilmiştir. Yine, yarış ve yarışmalar sırasında aşırı zorlanan atların solunum sisteminde özellikle trachea-bronş-bronşiyellerde ve ciğerlerinde kanamalar olduğu bildirilmiştir. Engelli koşunun normal yarıştan \%20 daha fazla ölüm riski taşıdığı kaydedilmektedir. Engelli koşularda yarış süresinin diğer yarışlardan daha uzun tutulması ve jokeylerin daha ağır olmaları bu duruma neden olmaktadır. Bu yüzden, yarış sırasında yorulan atların düşmesi, kendilerini ve jokeylerini sakatlamaları daha fazla söz konusu olmaktadır (53).

Spor atları yapılan işin zorluğu, hassas yapıları ve stres koşulları nedeniyle çeşitli hastalık ve problemle karşılaşmaktadırlar. Bu nedenle atların ruhsal, zihinsel ve bedensel sağlıkları yarış ve yarışma performansını doğrudan etkilemektedir. Spor atları sadece hastalandıklarında değil; periyodik olarak hareket, solunum, dolaşım ve sindirim sistemi başta olmak üzere tüm sistemlerinin kontrolüne ihtiyaç duyarlar. Sağlık kontrollerinde görüntüleme teknikleri, biyokimyasal kan testleri ve gerekli hormonal testler yapılmalı, çeşitli besin öğelerinin düzeylerine bakılmalı, iç parazitler yönünden tetkikler gerçekleştirilmelidir. Periyodik antiparaziter uygulamalar ve aşılamalar zamanında yapılmalı, hastalık oluşturacak şartlar ve etkenler ortadan kaldırılmalı, gerekli mineral ve vitamin takviyeleri sağlanmalıdir $(25,46,53)$.

\section{Sonuç}

Kantitatif bir karakter olan yarış ve yarışma performansının belirlenmesi sportif atçllı̆̆ın ve atlı sporların geliştirilmesi bakımından önem taşımaktadır. Yüksek yarış ve 
yarışma performansının geliştirilmesi için bu özelliğe ait fenotipik ve genotipik parametrelerin bilinmesi, bunlara etki eden çevresel faktörlerin dikkate alınması ve özelliklerin kalıtım derecesinin ortaya konulması gerekmektedir. Atların yarış ve yarışma performansına etki eden en önemli faktörler ırk, yaş, cinsiyet, handikap ağırlı̆̆ı, yarışlarda pist ve yarışmalarda parkur yapısı, yarışlarda mesafe ve engel atlama yarışmalarında yükseklik, binicinin yeteneği, ana yaşı, beden kondisyonu, doğum ağırlığı, bakım ve besleme ile antrenmandır. Türkiye'de yarış ve yarışmalarda başarı elde etmek için en fazla atların baba hattının performansına ve kısmen idmanlara önem verildiği, diğer faktörlerin ise genellikle göz ardı edildiği gözlemlenmektedir. Atlardan yüksek performans ve uluslararası başarılar elde etmek için genetik kapasitesi iyi atlar yetiştirilmesi yanında, performansa etki eden çevresel koşulların da optimum seviyeye çıkarılması önemli ve gereklidir.

\section{Kaynaklar}

Akçapınar, H., Özbeyaz, C., 1999. Hayvan Yetiştiriciliği Temel Bilgileri. Kariyer Matbaacılık, Ankara.

Aksüyek, B., 1990. Devlet Haraları Orijinli Safkan Arap Atlarının Yarış Performanslarının Gelişimi ve Bunu Etkileyen Faktörler. Doktora Tezi, Ankara Üniv. Sağlık Bilimleri Enstitüsü. Ankara.

Alpan, O., 1993. Sığır Yetiştiriciliği ve Besiciliği. 3. Basım, Medisan yayınevi, Ankara.

Anonim, 2007a. TBF Engel Atlama Yarısma Talimatı. Türkiye Binicilik Federasyonu. Ankara.

Anonim, 2007b.TBF At Terbiyesi Yarısma Talimatı. Türkiye Binicilik Federasyonu.

Anonim, 2009. TBF Genel Talimatı. Türkiye Binicilik Federasyonu. Ankara.

Anonim, 2011. At Yarışları Yönetmeliği. 19 Nisan 2011 tarih ve 27910 sayılı Resmi Gazete.

Anonim, 2013. Hayvanlarda davranış. http://mebk12. meb.gov.tr/meb_iys_dosyalar/14/05/132943/dosyalar/2013_01/22023347_hayvanlardadavran.pdf. Erişim
Tarihi: 22.06.2015.

Anonim, 2014. What is hypotherapy. http://www.answers. com/Q/What_type_of_horse_is_the_most_commonly_ used_for_hippotherapy. Erişim Tarihi 18.10.2014.

Anonim, 2017. At Yarışları Genel Hükümleri. medya. tjk.org/medyaftp/docs/Genhuk_2017.pdf. Erişim Tarihi: 18.12.2017.

Arıtürk, E., Akandır, M., 1984. Atlarda kantitatatif karekterlerin seçiminde dikkat edilmesi gereken temel kurallar. Lalahan Zootekni Araştırma Dergisi, 24, 74-83.

Arpacık, R., 1996. At Yetiştiriciliği. Medisan Yayınevi, Ankara.

Barron, J.K., 1995. The effect of maternal age and parity on the racing performance of Throughbred horses. Equine Vet Jour., 27, 73-75.

Batu, S., 1938. Türk Atları ve At Yetiştirme Bilgisi. Recep Ulusoğlu Basımevi, Ankara.

Breed, M.D., Moore, J., 2015. Animal Behavior. Nobel Akademik Yayıncılık. Ankara.

Carroll, C.L., Huntington, PJ., 1988. Body condition scoring and weight estimation of horses. Equine Vet Jour., 20, 41-45.

Chrazanowski, S., Koeboke, K., 1993. Estimation of breeding value of Thoroughbred horses on the basis of racing performance of their progeny at the age 2 and 3 years. Anim. Breed. Abst., 62, 7.

Chrazanowski, S., Lojek, J., Kurek, A., 1998. The comparison of two methods of evaluating the racing performance of Arabian horses. Anim. Breed Abst., 66,4.

Cothran, E.G., Maccluer, J.W., Weitkamp, L.R., Pfennig, D.W., Boyce, A.J., 1984. Inbreeding and reproductive performance in Standardbred horses. The Journal of Heredity. $75,220-224$.

Ekiz, B., Koçak, O., Yılmaz, A., 2005. Phenotypic and gene- 
tic parameter estimates for racing traits of Thoroughbred horses in Turkey, Archiv Tierzucht, 48, 121-129.

Finocchio, E.J., 1986. Race performance and its relationship to birth rank and maternal age. In; Aksüyek, B. (1990). Devlet haraları orijinli safkan Arap atlarının yarış performanslarının gelişimi ve bunu etkileyen faktörler. Doktora Tezi, Ankara Üniv. Sağlık Bilimleri Enstitüsü. Ankara.

Garlinghouse, SE., Burrill, MJ., 1999. Relationship of body condition score to completion rate during $160 \mathrm{~km}$ endurance races. Equine Vet Jour., 31, 591-595.

Gómez, M.D, Menendez-Buxadera, A., Valera, M., Molina, A., 2010. Estimation of genetic parameters for racing speed at different distances in young and adult Spanish Trotter horses using the random regression model. J Anim Breed Genet., 127, 385-94.

Güllü, A., Güllü, E., 2001. Genel Antrenman Bilgisi Sportif Performansı Geliştirmenin Yolları, Umut Matbaacılık, Malatya.

Gültepe R., 2014. Sportif atlar-Atımın sağlığı. 17 Haziran 2014 Salı 1057 sayılı Yarış Dünyası Dergisi. http:// video.liderform.com.tr/sportif-atlar.html. Erişim Tarihi: 27.12.2017.

26.Harkins, J.D., Kamerling, S.G., 1993. Effect of race distance and competition on performance of Thoroughbred racehorses. Anim. Breed. Abst., 62, 1.

Hendricks, B.L., 1995. International Encyclopedia of Horse Breeds. University Oklahoma pres. Norman and London. USA.

Henneke, D.R., Potter, G.D., Kreider, J.L., Yeates, B.F., 1983. Relationship between condition score, physical measurements and body fat percentages in mares. Equine Vet Jour., 15, 371-372.

Hintz, R.L., 1977. Factors influencing racing performance of the Standardbred pacer. Dissertation Abst. Int. 38, 295.

Hintz, R.L., 1980. Genetics of performance in the horse. Journal of Anim. Sci., 51, 582-594.
Janczarek, I., Kedzierski, W., 2011. Is it a good idea to train fillies and colts separately? J Appl Anim Welf Sci., 14, 211 9.

Kiper, M.A., Kutsal, A., Kutluk. H., 1983. Arıkan Arap A Grubuna Özgü Koşularda Birincilik Kazanan Atlara İlişkin İstatistikler. Türkiye Jokey Kulübü Yayınları, Ankara.

Köseman, A., Özbeyaz, C., 2009. Some phenotypic and genetic parameters of racing performance in Arabian horses. Ankara Üniv Vet Fak Derg., 56, 219-224.

Küçük, O., 2006. Koşu ve iş atlarının beslenmesi. J Fac Vet Med Univ Erciyes. 3, 43-51.

Langolish, B., 1980. Heritability of racing ability in Thoroughbreds - A review. Livestock Production Science. 7, 591-605.

Lee, K.J., Park, K.D., Kang, M.S., Choi, W.S., Kim, T.J., 1995. Sex age adjustment factors for racing time of Thoroughbred horses. Anim. Breed. Abstr. 63, 9.

Martin, G.S., Strand, E., Kearney, M.T., 1996. Use of statistical models to evaluate racing performance in Thoroughbreds. J Am Vet Med Assoc., 209, 1900-6.

McDonnell, S.M., 2015. Normal and abnormal behavior of stabled horses. http.//www.agricultura.alberta.ca. Erişim Tarihi: 22.06.2015.

Meinardus, H., Bruns, E., 1989. Use of riding even record for the selection of riding horses. 1. selection criteria and genetic parameters. Anim. Breed. Abs. 59, 10.

Mills, D.S. 1998. Personality and individual differences in the horse, their significance, use and measurement. Eq Vet J Suppl. 27, 10-13.

Mota, M.D.S, Oliveria, H.N., Silva, R.G., 1998. Genetic and environmental factors that affect best time of Thoroughbred horses in Brazil. Journal of Animal Breeding and Genetics, 115, 123-129.

Özbeyaz, C., Akçapınar, H., 2010. At Yetiştiriciliği Ders 
Notları. Ankara Üniversitesi Veteriner Fakültesi. Ankara.

Özen, D., Gürcan, İ.S., 2016. Determination of factors affecting the length of racing career of Arabian horses in Turkey. Ankara Üniv Vet Fak Derg. 63, 303-309.

Physick-Shard, P.W., Russell, M., 1986. Career profile of the Canadian Standardbred. 3. Influence of temporaly absence from racing and season. Canadian Journal of Veterinary Research. 50, 471-478.

Ricard, A., Bruns, E., Cunningham, E.P., 2000. The Genetics of the Horse, p. 411-438, Editors A.T. Bowling and A. Ruvinsky, CAB International, Oxon, UK.

Sel, T., Fidanc1 U.R. 2017. Spor Atlarında Performans Artırıcı Maddelerin Analizleri Ve Önemi. VET348. http://80.251.40.59/veterinary.ankara.edu.tr/fidanci/Ders_Notlari/SA-Spor_Atlari.pdf. Erişim Tarihi 27.12.2017.

Štrbac, L.J., Trivunović, S., Baban, M., 2015. Environmental factors affecting racing time of Trotter horses in Serbia. Poljoprivreda. 21, 178-18.

Temurlenk, Ö., 1991. At Terbiyesi Eğitimi. Ankara.

Thiruvenkadan, A.K., Kandasamy, N., Panneerselvam, S., 2009. Inheritance of racing performance of Thoroughbred horses. Livestock Science, 121, 308-26.

Veno, T. Motoyosi, S., Tanaka, R., 1991. Heritability of racing performance of Thoroughbreds. Animal Breed. Abst. 61,5 .

Violette, K., Wilmarth, M.A. 2014. Hippotherapy: A therapeutic treatment strategy. gallopnyc.org/.../Hippotherapy-art-Violette.do. Erişim Tarihi: 16.10.2014.

Willham, R.L, Wilson, D,E., 1991. Genetic predictions of racing performance in Quarter horses. Jour Anim Sci., 69, 3891-3894.

Yücel, D., 2015. At yarışlarında kullanılan atlar hakkında bilmediklerimiz. https:/gaiadergi.com/at-yarislarinda-kullanilan-atlar-hakkindabilmedikleriniz. Erişim Tari- hi: 27.12.2017.

Zeeb, K., Schnitzer, U., 1997. Housing and training of horses according to their species. Livest Prod Sci., 49, 181-189. 